\title{
Use of Sugammadex after Neostigmine Incomplete Reversal of Rocuronium-Induced Neuromuscular Blockade
}

\author{
Cássio Campelo de Menezes ${ }^{1}$, Lilian Akemi Moore Peceguini ${ }^{2}$, Enis Donizetti Silva ${ }^{3}$, \\ Claudia Marquez Simões, TSA/TE-AMIB ${ }^{4}$
}

Summary: Menezes CC, Peceguini LAM, Silva ED, Simões CM - Use of Sugammadex after Neostigmine Incomplete Reversal of RocuroniumInduced Neuromuscular Blockade.

Background and objectives: Neuromuscular blockers (NMB) have been used for more than half of a century in anesthesia and have always been a challenge for anesthesiologists. Until recently, the reversal of nondepolarizing neuromuscular blockers had only one option: the use of anticholinesterase agents. However, in some situations, such as deep neuromuscular blockade after high doses of relaxant, the use of anticholinesterase agents does not allow adequate reversal of neuromuscular blockade. Recently, sugammadex, a gamma-cyclodextrin, proved to be highly effective for reversal of NMB induced by steroidal agents.

Case report: A female patient who underwent an emergency exploratory laparotomy after rapid sequence intubation with rocuronium 1.2 mg.kg-1. At the end of surgery, the patient received neostigmine reversal of NMB. However, neuromuscular junction monitoring did not show the expected recovery, presenting residual paralysis. Sugammadex 2 mg. $\mathrm{kg}^{-1}$ was used and the patient had complete reversal of NMB in just 2 minutes time.

Conclusion: Adequate recovery of residual neuromuscular blockade is required for full control of the pharynx and respiratory functions in order to prevent complications. Adequate recovery can only be obtained by neuromuscular junction monitoring with TOF ratio greater than 0.9 . Often, the reversal of NMB with anticholinesterase drugs may not be completely reversed. However, in the absence of objective monitoring this diagnosis is not possible. The case illustrates the diagnosis of residual NMB even after reversal with anticholinesterase agents, resolved with the administration of sugammadex, a safe alternative to reverse the NMB induced by steroidal non-depolarizing agents.

Keywords: Neuromuscular Blockade; Neostigmine; Postoperative Complications.

\section{INTRODUCTION}

Neuromuscular blockers (NMB) have been used for more than half of a century in anesthesia, but always presenting a challenge for anesthesiologists. In 1954, a study by Beecher and Todd showed that in a universe of nearly 600,000 anesthetic procedures between 1948 and 1952, the use of muscle blocking increased by six times the risk of death during the perioperative period ${ }^{1}$.

With the evolution of both neuromuscular blocking and neuromuscular junction monitoring, the management of muscle relaxation became safer and more efficient. However, recent studies show that residual neuromuscular blockade remains a reality today ${ }^{2-4}$.

Received from São Paulo Serviços Médicos de Anestesiologia (SMA), Brazil.

1. Anesthesiologist, São Paulo Serviços Médicos de Anestesiologia (SMA); Responsible for CET da SMA / Hospital Sírio Libanês

2. Anesthesiologist, SMA / Hospita; Preceptora do CET da SMA / Hospital Sírio Libanês

3. Anesthesiologist, SMA; Co-responsible of CET da SMA / Hospital Sírio Libanês

3. Anesthesiologist, SMA; Co-responsible of CET da SMA / Hospital Sírio Libanês

4. Coordinator, Anesthesiology Department, Instituto do Câncer do Estado de São Paulo
(ICESP), State Department of Health and Faculdade de Medicina da Universidade de São Paulo; Co-responsible of CET da SMA / Hospital Sírio Libanês

Submitted on December 24, 2010.

Approved on November 23, 2011.

Correspondence to:

Claudia Marquez Simões, MD

Rua Dona Adma Jafet, $50 \mathrm{cj} 31$

Bela Vista

01308050 - São Paulo, SP, Brazil.

E-mail: claucms@terra.com.br
In clinical practice, we are often faced with situations that are beyond the normal pattern, such as the presence of residual neuromuscular blockade, even after reversal with anticholinesterase drug ${ }^{3}$. This case report illustrates a situation of residual neuromuscular blockade, even after reversal with anticholinesterase agents, which could be adequately managed with a new specific reversal agent, sugammadex.

\section{CASE REPORT}

Female patient, 65 years old, $55 \mathrm{~kg}, 1.57 \mathrm{~m}$, with systemic hypertension. Hospitalized for three days due to an obstructive acute abdomen, secondary to sub-intestinal obstruction of unknown etiology, with progressive deterioration and requiring an exploratory laparotomy.

The patient was admitted to the operating room conscious and oriented, with significant abdominal distension, blood pressure $160 \times 78 \mathrm{~mm} \mathrm{Hg}$, heart rate $94 \mathrm{bpm}, \mathrm{SpO}_{2}=94 \%$ on room air. We opted for general anesthesia with rapid sequence induction. After denitrogenation for 3 minutes, anesthesia was induced with sufentanil $0.3 \mu \mathrm{g} \cdot \mathrm{kg}^{-1}$, propofol $2.5 \mathrm{mg} \cdot \mathrm{kg}^{-1}$, and rocuronium $1.2 \mathrm{mg} \cdot \mathrm{kg}^{-1}$. Intubation was performed without complications. Anesthesia was maintained with propofol targetcontrolled infusion and remifentanil by continuous infusion. 
The surgical procedure ended 90 minutes after induction of anesthesia. Neuromuscular junction monitoring was performed with train-of-four (TOF-GE Datex-Ohmeda) sequence, and only two responses were obtained. We dministered neostigmine $50 \mu \mathrm{g} \cdot \mathrm{kg}^{-1}$ and atropine $30 \mu \mathrm{g} \cdot \mathrm{kg}^{-1}$, and about 3 minutes after, TOF was already at T4/T1 ratio of 0.3 . After 45 minutes, there was no recovery of muscle activity ideal for a safe extubation $(\mathrm{T} 4 / \mathrm{T} 1$ remained $<0.4)$. Then, sugammadex $2.0 \mathrm{mg} \cdot \mathrm{kg}^{-1}$ was administered by iv bolus. After 2 minutes of administration, the ratio reached 0.9 and after three minutes, it was 0.95 . The patient was extubated uneventfully and transferred to the anesthesia recovery unit where she remained for 2 hours with no sign of residual neuromuscular blockade.

\section{DISCUSSION}

Rocuronium is a steroidal non-depolarizing neuromuscular blocking agent of intermediate action. It is a safe alternative to succinylcholine for rapid sequence intubation ${ }^{5}$. With a dose of $1.2 \mathrm{mg} \cdot \mathrm{kg}^{-1}$, the pharmacodynamic profile of the drug is modified by reducing the onset of action ( $55 \pm 14 \mathrm{sec}$ ), but extending its duration (average of $73 \mathrm{~min}$, ranging from 38 to $150 \mathrm{~min})^{6}$. This might be the main reason why TOF had only two responses 90 minutes after rocuronium administration. There are also reports in literature showing that, in elderly patients and female, the time of action of NMB may increase ${ }^{7}$.

Besides the previously mentioned factors, the surgical time was short. Therefore, we decided to reverse muscle blockade. Initially, we decided to use neostigmine with atropine at the usual dose (40-70 $\left.\mu \mathrm{g} \cdot \mathrm{kg}^{-1}\right)$, which has onset within 1 minute, peak action in about 10 minutes, and 20 to 30 of duration ${ }^{7}$. In deep blocks, neostigmine (post-tetanic count [PTC] 1 to 2 responses) does not promote complete reversal of muscle blockade and may have some adverse effects, such as bradycardia, tachycardia, bronchoconstriction, dry mouth, nausea, and vomiting ${ }^{8-10}$. Moreover, the time to obtain a TOF stimulation ratio of 0.9 with its use may be greater ${ }^{11}$.

Another relevant aspect in this case is the use of neuromuscular junction monitoring. Unfortunately, this practice is not common. In recent work, it was shown that approximately $20 \%$ of anesthesiologists in Europe and $10 \%$ in North America never used neuromuscular block monitors ${ }^{12}$.

Residual neuromuscular block (RNMB) is defined as the presence of signs and symptoms of muscle weakness during postoperative period after NMB administration. Its incidence is quite variable in literature, considering the various factors that may affect the evaluation of residual block. A recent metanalysis provides a little more precise idea on this issue ${ }^{13}$.
The authors analyzed 3,375 patients in 24 studies between 1979 and 2005. They found that NMB antagonists were used in $62.1 \%$ of patients and monitoring (qualitative and quantitative) in $24.4 \%$. It was concluded that in cases where there was reversal of the blocking agent, the incidence of RNMB was $12 \%$ (TOF < 0.7 ) and $41 \%$ (TOF $=0.9$ ). Furthermore, the influence of monitors on residual block reduction was not defined. We believe, however, that its use is of paramount importance for muscle blockade management, particularly to define whether there is need for reversal and if the patient is already in safe conditions for extubation.

Currently, there is a new option to antagonize the action of rocuronium ${ }^{14}$. Sugammadex is a modified gamma-cyclodextrin with a volume of distribution of 10 to $15 \mathrm{~L}$, half-life of 2 hours, and low protein binding. It has a spatial conformation with a water-soluble outer portion and lipophilic central region, which encapsulates the rocuronium molecule by non-covalent bonding and forms a new molecular complex, which does not act on the neuromuscular junction ${ }^{15}$.

When administered, sugammadex binds at a $1: 1$ ratio to free steroidal NMB in plasma. Therefore, plasma concentration falls dramatically and shifts the neuromuscular junction blocking agent by the concentration gradient generated.

Sugammadex dosage varies according to the depth of muscle blockade. In moderate neuromuscular block (reappearance of T2), 2 mg. $\mathrm{kg}^{-1}$ is used. In deep block (1-2 PTCs), $4 \mathrm{mg} \cdot \mathrm{kg}^{-1}$ is used. In case of immediate reversal (3 minutes after administration of $1.2 \mathrm{mg} \cdot \mathrm{kg}^{-1}$ ), $16 \mathrm{mg} \cdot \mathrm{kg}^{-1}$ is used. Several studies have shown the efficacy and speed of rocuronium reversal.

The most common adverse reactions of sugammadex are post-surgical pain, nausea, vomiting, pyrexia, back pain, headache, sore throat, cough, and constipation ${ }^{16-17}$. The patient showed no such changes during anesthetic recovery.

\section{CONCLUSION}

Sugammadex has shown to be a safe drug, fast acting, and effective for reversal of neuromuscular block, avoiding the associated complications. It is therefore a new alternative for the reversal of muscular blockade induced by steroidal agents, more specifically for rocuronium. We emphasize that the diagnosis and appropriate treatment were only possible thanks to the use of neuromuscular junction monitoring, which allowed, with the use of sugammadex, a safe extubation. 


\section{REFERENCES}

1. Beecher HK, Todd DP - A study of the deaths associated with anesthesia and surgery: based on a study of 599,548 anesthesias in ten institutions 1948-1952, inclusive. Ann Surg, 1954;140:2-35.

2. Murphy GS, Szokol JW, Marymont JH, Greenberg SB, Avram MJ, Vender JS - Residual neuromuscular blockade and critical respiratory events in the postanesthesia care unit. Anesth Analg, 2008;107:130137.

3. de Morais BS, de Castro CH, Teixeira VC, Pinto AS - Residual neuromuscular block after rocuronium or cisatracurium. Rev Bras Anestesiol, 2005;55:622-630.

4. Almeida MC - Neuromuscular blockers in Brazil. Rev Bras Anestesiol, 2004;54:850-864.

5. Taha SK, El-Khatib MF, Baraka AS et al. - Effect of suxamethonium vs rocuronium on onset of oxygen desaturation during apnoea following rapid sequence induction. Anaesthesia, 2010;65:358-361.

6. Magorian T, Flannery KB, Miller RD - Comparison of rocuronium, succinylcholine, and vecuronium for rapid-sequence induction of anesthesia in adult patients. Anesthesiology, 1993;79:913-918.

7. Xue FS, Tong SY, Liao X, Liu JH, An G, Luo LK - Dose-response and time course of effect of rocuronium in male and female anesthetized patients. Anesth Analg, 1997;85:667-671.

8. Srivastava A, Hunter JM - Reversal of neuromuscular block. Br J Anaesth, 2009;103:115-129.

9. Eikermann M, Zaremba S, Malhotra A, Jordan AS, Rosow C, Chamberlin $\mathrm{NL}$ - Neostigmine but not sugammadex impairs upper airway dilator muscle activity and breathing. Br J Anaesth, 2008;101:344349.

10. Cosar A, Yildiz C, Orhun E, Yanmis I, Ergun A, Tunay S - The effect of neostigmine and atropine combination on postoperative nausea and vomiting after arthroscopic surgery. Acta Orthop Traumatol Turc, 2005;39:341-344.

11. Blobner M, Eriksson LI, Scholz J, Motsch J, Della Rocca G, Prins ME - Reversal of rocuronium-induced neuromuscular blockade with sugammadex compared with neostigmine during sevoflurane anaesthesia: results of a randomised, controlled trial. Eur $\mathrm{J}$ Anaesthesiol, 2010;27:874-881.

12. Naguib M, Kopman AF, Lien CA, Hunter JM, Lopez A, Brull SJ - A survey of current management of neuromuscular block in the United States and Europe. Anesth Analg, 2010;111:110-119.

13. Naguib M, Kopman AF, Ensor JE - Neuromuscular monitoring and postoperative residual curarisation: a meta-analysis. $\mathrm{Br} \mathrm{J}$ Anaesth, 2007;98:302-316

14. [No authors listed] - Molecule of the month. Sugammadex sodium. Drug News Perspect. 2007;20:591-592.
15. Abrishami A, Ho J, Wong J, Yin L, Chung F - Sugammadex, a selective reversal medication for preventing postoperative residual neuromuscular blockade. Cochrane Database Syst Rev, 2009:CD007362.

16. Peeters PA, van den Heuvel MW, van Heumen E et al. - Safety, tolerability and pharmacokinetics of sugammadex using single high doses (up to $96 \mathrm{mg} / \mathrm{kg}$ ) in healthy adult subjects: a randomized, double-blind, crossover, placebo-controlled, single-centre study. Clin Drug Investig, 2010;30:867-874.

17. Malinovsky JM, Plaud B, Debaene B, Mertes PM - [Do we know all indications and side effects of sugammadex?]. Ann Fr Anesth Reanim, 2011;30(10):709-710. 